\title{
Pharmacological differences between memory consolidation of habituation to an open field and inhibitory avoidance learning
}

M.R.M. Vianna1,

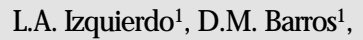

M.M. de Souza',

C. Rodrigues ${ }^{1}$,

M.K. Sant'Anna',

J.H. Medina ${ }^{2}$ and

I. Izquierdo 1

\author{
${ }^{1}$ Centro de Memória, Departamento de Bioquímica, \\ Instituto de Ciências Básicas da Saúde, \\ Universidade Federal do Rio Grande do Sul, Porto Alegre, RS, Brasil \\ 'Laboratorio de N eurorreceptores, Instituto de Biología Celular, \\ Facultad de Medicina, Universidad de Buenos Aires, Buenos Aires, Argentina
}

\section{Correspondence \\ M.R.M. Vianna \\ Centro de Memória \\ Departamento de Bioquímica \\ ICBS, UFRGS \\ Rua Ramiro Barcelos, 2600 \\ 90035-003 Porto Alegre, RS \\ Brasil \\ Fax: + 55-51-316-5540 \\ E-mail: mrmvianna@yahoo.com \\ Research supported by a travel grant from Agencia para el \\ Desarrollo Científico y Tecnológico \\ (Argentina), FAPERGS and PRO NEX. \\ L.A. Izquierdo, D.M. Barros and \\ M.M. de Souza are recipients of \\ CAPES fellowships, and M.R.M. \\ Vianna, C. Rodrigues and M.K. \\ Sant'Anna of CNPq fellowships.}

Received August 23, 2000

Accepted November 22, 2000

.................

\section{Abstract}

Rats implanted bilaterally with cannulae in the CA1 region of the dorsal hippocampus or the entorhinal cortex were submitted to either a one-trial inhibitory avoidance task, or to $5 \mathrm{~min}$ of habituation to an open field. Immediately after training, they received intrahippocampal or intraentorhinal $0.5-\mu 1$ infusions of saline, of a vehicle ( $2 \%$ dimethylsulfoxide in saline), of the glutamatergic $N$-methyl-D-aspartate (NMDA) receptor antagonist 2-amino-5-phosphono pentanoic acid (AP5), of the protein kinase A inhibitor Rp-cAMPs $(0.5 \mu \mathrm{g} / \mathrm{side})$, of the calcium-calmodulin protein kinase II inhibitor KN-62, of the dopaminergic $\mathrm{D}_{1}$ antagonist $\mathrm{SCH} 23390$, or of the mitogen-activated protein kinase kinase inhibitor PD098059. Animals were tested in each task $24 \mathrm{~h}$ after training. Intrahippocampal KN-62 was amnestic for habituation; none of the other treatments had any effect on the retention of this task. In contrast, all of them strongly affected memory of the avoidance task. Intrahippocampal Rp-cAMPs, KN-62 and AP5, and intraentorhinal Rp-cAMPs, KN-62, PD098059 and SCH23390 caused retrograde amnesia. In view of the known actions of the treatments used, the present findings point to important biochemical differences in memory consolidation processes of the two tasks.

\section{Key words}

- Habituation learning

- One-trial avoidance

- Memory consolidation

- Pharmacology of memory consolidation

- Hippocampus

- Entorhinal cortex

\section{Introduction}

Habituation to a novel environment is believed to be one of the most elementary forms of learning, in which the decreased exploration as a function of repeated exposure to the same environment is taken as an index of memory $(1,2)$. This is normally studied in two or more brief sessions of exposure to an open field or similar environment (1-5). Rather curiously, however, habituation to an open field has been very little studied with respect to pharmacological and biochemical mechanisms of memory consolidation, in spite of evidence showing that it clearly depends on the hippocampus (1-6).

The consolidation of long-term memory of one-trial inhibitory avoidance starts im- 
mediately after acquisition (7) and lasts several hours (6-9). It coexists with, but is not dependent upon, short-term memory processes, which operate through biochemical systems of their own (10-12). It relies on a sequence of biochemical events in the CA1 region that are very similar to those underlying long-term potentiation (LTP) in that same region (13). Long-term memory consolidation of inhibitory avoidance begins by activation of $N$-methyl-D-aspartate (NMDA), D,L- $\alpha$-amino-3-hydroxy-5-methyl-4-isoxalone propionate (AMPA) and metabotropic glutamate receptors $(3,6,14)$, followed by activation of calcium-calmodulin dependent protein kinase II (CaMKII) (5,15-17), protein kinase $\mathrm{C}$ (PKC) (6) and mitogen-activated protein kinase kinase (MAPKK) $(12,18)$, and by an early peak of protein kinase A (PKA) activity and increased levels of nuclear phosphorylated cAMP response element binding protein (P-CREB) $(8,11)$, among other events (6). The chain of events culminates at 3-6 $\mathrm{h}$ with a second peak of activation of the cAMP/PKA/P-CREB signaling pathway $(6,8,19)$. Both PKA/P-CREB peaks are regulated by dopamine $\mathrm{D}_{1}$ receptors $(10,20,21)$. Some of these molecular steps also take place in the entorhinal cortex and other brain regions $(6,20)$.

Similar findings have been obtained in spatial tasks $(16,22)$, in a water-finding task (5), and in contextual fear, although the timing of some of the biochemical events may differ from task to task $(23,24)$. All these findings have been validated by observations in transgenic mice with altered expression of proteins involved in the processes mentioned above: the $\mathrm{R} 1$ subunit of NMDA receptors (25), CaMKII (26), PKA (27), and CREB $(19,28)$. Such animals show deficient hippocampal LTP and hippocampal-dependent learning.

The few studies on the pharmacology and biochemistry of the hippocampus or its connections with respect to habituation to a novel environment include: a) a deleterious influence of post-training intrahippocampal AP5, muscimol, KN-62 or scopolamine, and an enhancing effect of glutamate and oxotremorine on retention of very brief (1 min) habituation sessions by rats in a small novel environment (3); b) a reduction of the acquisition of habituation by pretraining intrahippocampal AP5 or KN-62 administration in 2-min training sessions in an open field (4); c) importantly, an increase of extracellular hippocampal acetylcholine during and after 10-min habituation sessions in an open field (2), and amnestic effect of scopolamine on habituation in such sessions. Other evidence points to a dual cholinergic muscarinic and nicotinic receptor involvement in the enhancing effect of glucose (29) and the amnestic effect of insulin (30) on retention of 10-min open-field habituation sessions in mice.

For biochemical and pharmacological studies, clearly 5- or 10-min habituation sessions $(1,2,29-31)$ are preferable to shorter sessions. First, in 1- or 2-min sessions it is difficult to discriminate between effects on the detection of novelty (4) and effects on the memory of habituation. Both depend on the hippocampus $(2,24,32)$. Second, in 5- or 10 -min sessions the retention of habituation is much stronger $(24,31)$ than after 1- or 2 min sessions (3); after these, the second session might well represent merely a continuation of acquisition (4) rather than retention testing $(1,2)$.

In the present investigation we studied the effect of the post-training intrahippocampal or intraentorhinal administration of several drugs known to act upon the core mechanisms of consolidation of inhibitory avoidance, both on that task, and on the retention of a 5-min session of habituation to an open field. The drugs studied were the PKA inhibitor Rp-cAMPs, the CaMKII inhibitor KN-62, the MAPKK inhibitor PD098059, the dopaminergic $\mathrm{D}_{1}$ antagonist SCH23390, and the glutamatergic NMDA receptor antagonist 2-amino-5-phosphono 
pentanoic acid (AP5). The specific doses used here were chosen precisely because they had all been previously shown to have clear effects on memory of inhibitory avoidance $(3,6,10,11,17,18,20,21)$ or other tasks $(5,16)$ when infused into the hippocampus or the entorhinal cortex.

\section{Material and Methods}

A total of 410 male Wistar rats (age, 2.53 months; weight, 220-340 g) from our own breeding colony were used. They were housed in plastic cages, 5 to a cage, with water and food freely available, under a $12-$ $\mathrm{h}$ light/dark cycle (lights on at 7:00 h). Of these, 205 were implanted under deep thionembutal anesthesia with 30 -gauge guides $1.0 \mathrm{~mm}$ above the CA1 area of the dorsal hippocampus (A -4.3, L +4.0, V 3.4), and the other 205 were implanted $1.0 \mathrm{~mm}$ above the surface of the entorhinal cortex (A -7.0, L +5.0 , V 8.4) (coordinates are in $\mathrm{mm}$, according to the Paxinos and Watson atlas) (33).

After recovery from surgery, 250 of the animals (125 with cannulae in the CA1 region, 125 with cannulae in the entorhinal cortex) were placed in a $40 \times 60 \mathrm{~cm}$ open field surrounded by $50-\mathrm{cm}$ high walls made of brown plywood with a frontal glass wall. The floor of the open field was divided into 12 equal rectangles by black lines. Animals were gently placed on the left rear quadrant, and left to explore the arena for $5 \mathrm{~min}$. Immediately following this, the animals were withdrawn and received an infusion into either the CA1 or the entorhinal cortex (see below), taken back to their home cage, and $24 \mathrm{~h}$ later submitted again to a similar openfield session (test session).

Crossings of the black lines and rearings performed in both sessions were counted. The decrease in the number of crossings and rearings between the two sessions was taken as a measure of the retention of habituation $(1-3,5)$.

One hundred and sixty animals (80 with cannulae in the hippocampus, 80 with cannulae in the entorhinal cortex) were trained in one-trial step-down inhibitory avoidance as described elsewhere $(3,10,14,20,21,31)$. Briefly, the animals were placed on a $2.5-\mathrm{cm}$ high and 7-cm wide platform facing a $43 \mathrm{x}$ $25 \mathrm{~cm}$ grid of bronze bars spaced $1 \mathrm{~cm}$ apart. Latency to step down with their four paws onto the grid was measured. A 0.4-mA, 1-s scrambled footshock was immediately delivered to the grid (training session) and immediately after this the rats received the brain infusions (see below), were taken back to their home cages, and $24 \mathrm{~h}$ later were placed again on the platform and a test session was carried out. This session was procedurally identical to the training session except that the footshock was omitted.

Infusion cannulae (27 gauge) were fitted into the guide cannulae immediately after training. Infusions were performed through a microsyringe attached to the cannulae with a polyethylene tube. The tip of the infusion cannulae protruded $1 \mathrm{~mm}$ beyond that of the guide, so that it reached exactly the pyramidal cell layer of the CA1 region. Infusions were carried out over $30 \mathrm{~s}$, after which the cannulae were left in place for another $15 \mathrm{~s}$, first on one side and then on the other. Thus, the infusion procedure took slightly over 90 $\mathrm{s}(5,10,20,21)$. Infusions like these reach an area of approximately $1 \mathrm{~mm}^{3}$ and diffuse away from the infusion site in less than 60 $\min (10,20,21,34)$ (Figure 1).

The treatments were saline, vehicle ( $2 \%$ dimethylsulfoxide in saline), the glutamatergic NMDA receptor antagonist AP5 $(5.0 \mu \mathrm{g} /$ side), the PKA inhibitor Rp-cAMPs $(0.5 \mu \mathrm{g} /$ side), the CaMKII inhibitor KN-62 (3.6 ng/ side), the dopaminergic $\mathrm{D}_{1}$ antagonist $\mathrm{SCH} 23390(0.5 \mu \mathrm{g} /$ side $)$, and the MAPKK inhibitor PD098059 $(50 \mu \mathrm{M})$. SCH23390, PD098059 and KN-62 were dissolved in the vehicle; AP5 and Rp-cAMPs were dissolved in saline. Infusion volume was $0.5 \mu 1$ in all cases.

Two to $24 \mathrm{~h}$ after the end of the behavior- 


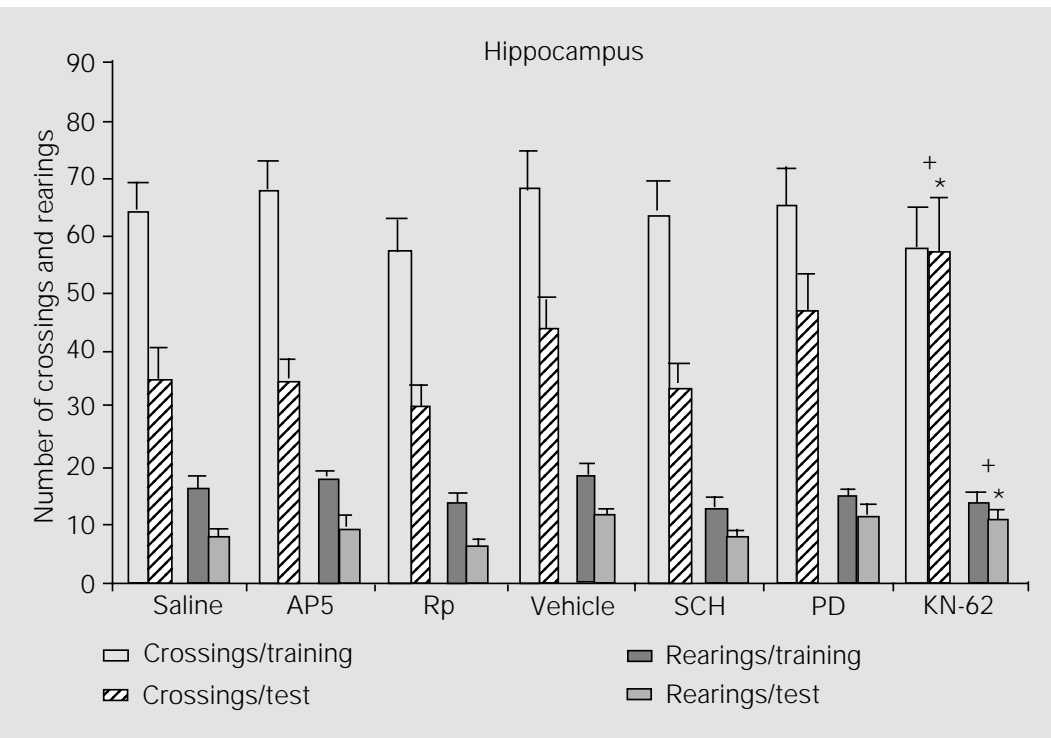

Figure 1 - Crossings and rearings of training and test session performance (mean \pm SEM) in 5 -min sessions in an open field with a $24-h$ interval between sessions. $\mathrm{N}=14-16$ per group. The animals had cannulae implanted bilaterally in the CA1 region of the dorsal hippocampus. Immediately after training they received through the cannulae $0.5-\mu$ infusions of saline, the glutamatergic NMDA receptor antagonist AP5 $(5.0 \mu \mathrm{g} / \mathrm{side})$, the PKA inhibitor RpcAMPs (Rp, $0.5 \mu \mathrm{g} / \mathrm{side}$ ), vehicle ( $2 \%$ dimethylsulfoxide in saline), the CaM KII inhibitor KN62 (3.6 ng/side), the MAPKK inhibitor PD098059 (PD, $50 \mu \mathrm{M})$ or the dopaminergic $\mathrm{D}_{1}$ antagonist $\mathrm{SCH} 23390$ ( $\mathrm{SCH}, 0.5 \mu \mathrm{g} / \mathrm{side}$ ). AP5 and Rp were dissolved in saline; all the other drugs were dissolved in vehicle. $\mathrm{KN}-62$ caused retrograde amnesia; all the other treatments were ineffective. $* \mathrm{P}<0.05$ compared to vehicle (Duncan test); ${ }^{+}$no differences between training and test rearings and crossings ( $P>0.1$, Duncan test).

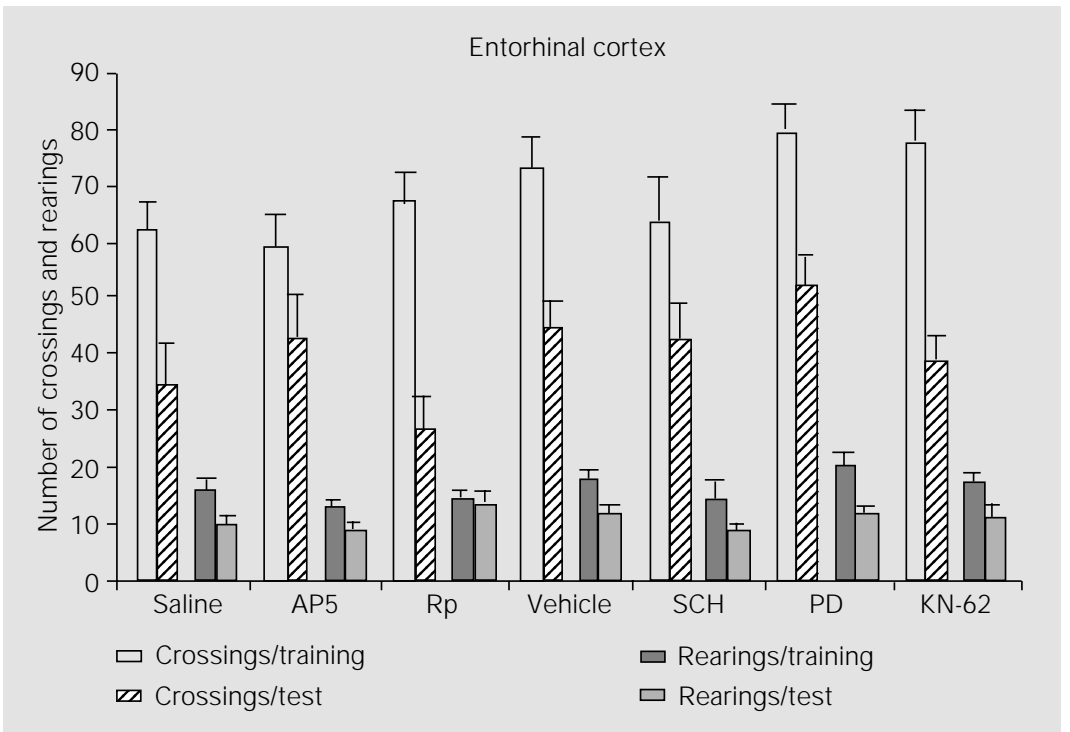

Figure 2 - Same as Figure 1, but using bilateral infusions into the entorhinal cortex. $\mathrm{N}=14$ 17 per group. None of the treatments had any effect on retention test performance of the habituation task. al procedures, $0.5 \mu \mathrm{l}$ of a solution of $4 \%$ methylene blue in saline was infused as indicated above into the implanted sites. Animals were sacrificed by decapitation $1 \mathrm{~h}$ later and their brains withdrawn and stored in formalin for histological localization of infusion sites as explained elsewhere $(4,6,10$, 20,21). Infusion placements were correct (i.e., within $1.5 \mathrm{~mm}^{3}$ of the intended site) in 202 of the animals implanted in the CA1 region and in 204 of those implanted in the entorhinal cortex. Statistical analysis was carried out only in the animals with correct cannula placements.

Parametric statistics were used: one-way ANOVA followed by the Duncan multiple range test for comparisons among groups, and the Student $t$-test for training-test performance comparisons within each group. Unlike most experiments using the one-trial avoidance task $(3,4,10,14,20,21)$, no ceiling was imposed on retention test latencies, whose range was 1.3 to $98.7 \mathrm{~s}$ across all groups.

\section{Results}

Results of habituation studies are shown in Figures 1 (hippocampus) and 2 (entorhinal cortex). Results of inhibitory avoidance are shown in Figures 3 (hippocampus) and 4 (entorhinal cortex).

There was good evidence for habituation in all groups, except the one treated with KN-62 into the hippocampus. All trainingtest differences in crossings and rearings were significant by the Duncan test at $\mathrm{P}<0.01$ or $\mathrm{P}<0.05$, respectively, except in this group. There were no differences among groups in training or test session performance in the animals that received intrahippocampal or intraentorhinal treatments, except for crossings and rearings in the test session of animals that received KN-62 in the hippocampus.

Retention of the one-way avoidance task was markedly impaired by Rp-cAMPs, KN- 
62 or AP 5 given into the CA1 region, and by Rp-cAMPs, KN-62, SCH23390 or PD098059 given into the entorhinal cortex.

\section{Discussion}

None of the treatments studied affected the retention of habituation to the open field, except intrahippocampal KN-62, which caused retrograde amnesia for this task, in confirmation of previous results (5). All of the treatments markedly affected retention of the one-trial avoidance task. Rp-cAMPs and $\mathrm{KN}-62$ caused retrograde amnesia for inhibitory avoidance when given into either structure, AP5 was amnestic when given into the CA1 region, and $\mathrm{SCH} 23390$ and PD098059 were amnestic when given into the entorhinal cortex. The findings on the avoidance task agree with previous reports $(3,10,11,17,18,20,21)$.

The effect of drugs given by intracerebral infusion such as those used here fades away with diffusion from the infusion site, which takes place within less than $1 \mathrm{~h}$ (34). Therefore, the present data suggest that the biochemistry of the early period of consolidation of habituation must be different from that of the avoidance task or others: in the first hour or so, at least, it does not involve LTP-like mechanisms sensitive to the treatments studied either in the CA1 region or in the entorhinal cortex as is the case for inhibitory avoidance memory $(6,19)$. Memory formation for habituation differs not only from one-trial avoidance, but also from contextual fear, spatial learning and other associative learning tasks in different species $(6,9,19$, $21,23,24,28,35)$, suggesting that associative and non-associative memories recruit different mechanisms for its formation. This idea is corroborated by a recent report from Mitchell et al. (36) who demonstrated that associative but not non-associative opioid tolerance is sensitive to cholecystokinin. The only treatment that had the same effect on inhibitory and habituation memory was in- trahippocampal KN-62, which of course suggests a role for hippocampal CaMKII in the consolidation of both $(5,15,17)$, as it has in other tasks $(1,6,19,26)$.

The results presented in this study are based on the effects of drugs given within a restricted period of time immediately posttraining and could suggest that differences

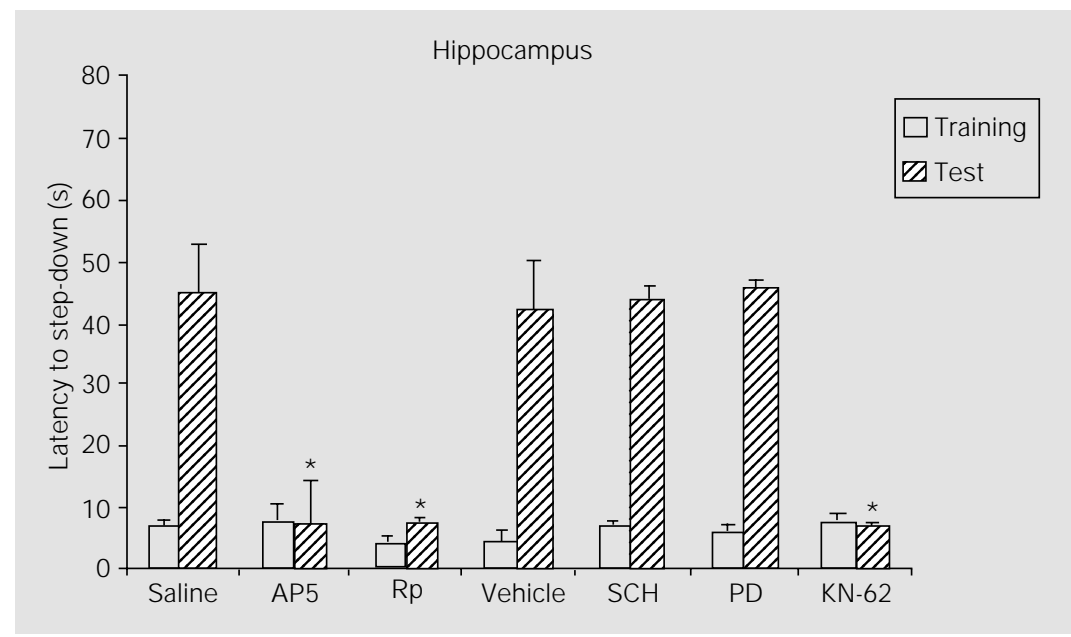

Figure 3 - Training and test session latency (mean \pm SEM) to step down in a one-trial stepdown inhibitory avoidance task. $\mathrm{N}=9-10$ per group. The animals had cannulae implanted bilaterally in the CAl region of the dorsal hippocampus. Immediately after training they received the same treatments as shown in Figure 1 or 2 . In this and in the following figure, differences among groups in training session scores were not significant $(P>0.1$, Duncan test). Rp, KN-62 and AP5 were amnestic. $* \mathrm{P}<0.001$ compared to saline or vehicle (Duncan test).

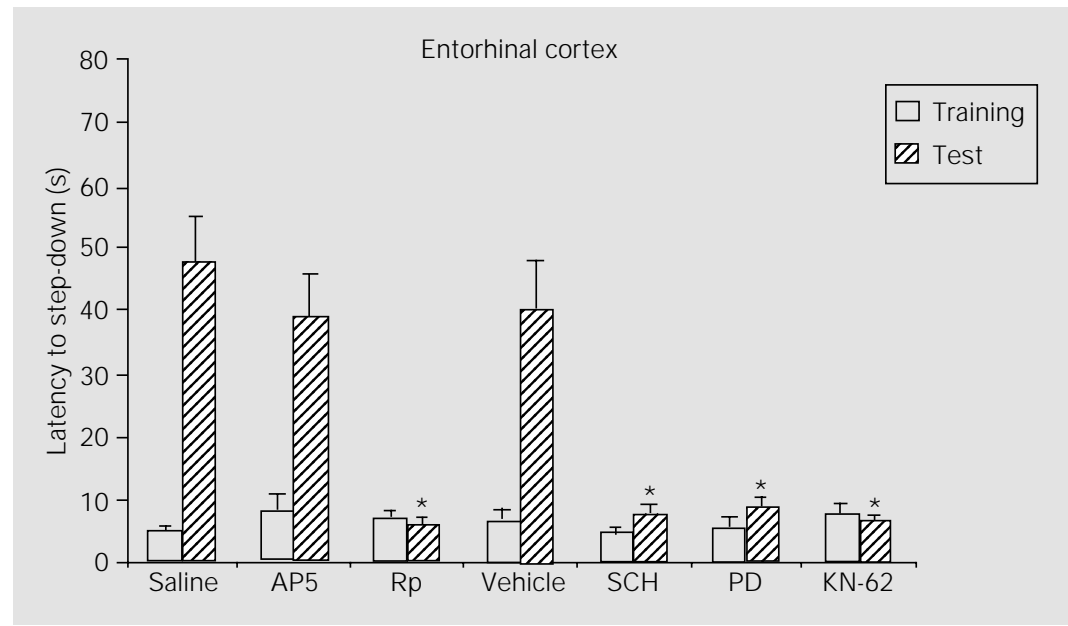

Figure 4 - Same as Figure 3, but using bilateral infusions into the entorhinal cortex. $\mathrm{N}=9$ or 10 per group. Rp, PD, $\mathrm{KN}-62$ and $\mathrm{SCH}$ were amnestic. $* \mathrm{P}<0.01$ compared to saline or vehicle (Duncan test). 
found between the tasks result from the delayed acquisition period of habituation and are restricted to the early consolidation period. To better characterize the temporal profile of inhibitory avoidance and habituation differences we have studied the effect of drugs acting upon the CaMKII, PKA, MAPKK cascades and de novo protein synthesis given into the hippocampus at different post-training intervals and found that differences between the two tasks extend through the consolidation period (35).

Bourtchouladze et al. (28) showed that contextual fear acquired with weak footshock stimulation is more sensitive to the depressant effect of anisomycin and Rp-cAMPs than the same task acquired with strong footshock stimulation. This led them to postulate that "stronger training paradigms" might recruit "a variety of signal transduction pathways immediately after training, presumably allowing sufficient genes to be turned on at the outset of training and leading to one consolidation period". It also might be the case that a stronger form of learning recruits different signaling pathways that interact and share common targets, as shown for PKA, PKC and MAPKK with respect to CREB phosphorylation (37). In this scenario, blockage of one of these redundant systems would not be enough to cancel memory formation, making memories more resistant to pharmacological interference. In agreement with this idea is the lack of effect of intrahippocampal AP5 on habituation described here as compared with the amnestic effect reported for this drug when 1-min habituation sessions were studied in a smaller environment (3).

Habituation acquired during 5 min could well be a "stronger" learning than the more stressful and pharmacologically labile inhibitory avoidance task. Training-test differences are more pronounced after 5-min sessions, as used here, or 10-min sessions, as used by Thiel et al. (1,2), than after 1- or 2min sessions $(5,10)$.

The lack of effect of receptor antagonists on habituation shown here, particularly AP5, when compared to earlier reports on shorter versions of the task (3), could be attributed to the delay introduced by the length of the training session. It is widely known that NMDA receptors are immediately activated at the time of induction of plastic events and for a few seconds afterwards, but not later $(3,6,7,13,14)$. It must be the case that posttraining infusion at the end of $5 \mathrm{~min}$ of habituation does not reach this initial receptor activation in time to avoid cellular stimulation, since we have recently shown that AP5 given 15 min before a 5-min habituation training session is capable of causing full amnesia for this task (35).

More detailed studies about the biochemistry of habituation are desirable. So far, few studies have been dedicated to this issue, including the findings by Thiel et al. (2) of increased acetylcholine release in the hippocampus and of changes in monoamine levels in other brain structures. It will be necessary to discriminate between effects on the detection of novelty (4) and effects on the memory of habituation. Five-min exposure to the open field $1 \mathrm{~h}$ prior to the retention test has been shown to influence inhibitory avoidance retention, and this effect is blocked by intrahippocampal infusions of AP5 and PD098059, but not by Rp-cAMPs prior to open-field exposure regardless of their effect on habituation or the lack of it (Izquierdo LA, Viola $\mathrm{H}$, Barros DM, Alonso M, Vianna MRM, Furman M, Levi de Stein M, Szapiro G, Rodrigues $\mathrm{C}$, Choi $\mathrm{H}$, Medina $\mathrm{JH}$ and Izquierdo I, unpublished results). These results, when compared to those obtained in the present study, strongly suggest a separation between the novel environment detection and the subsequent habituation. 


\section{References}

1. Thiel CM, Huston JP \& Schwarting RJ K (1998). Hippocampal acetylcholine and habituation learning. Neuroscience, 85 : 1253-1262.

2. Thiel CM, Müller CP, Huston JP \& Schwarting RJ K (1999). High versus low reactivity to a novel environment: behavioural pharmacology and neurochemical assessments. Neuroscience, 93: 243-251.

3. Izquierdo I, da Cunha C, Rosat R, Ferreira MBC, J erusalinsky D \& Medina J H (1992). Neurotransmitter receptors involved in memory processing by the amygdala, medial septum and hippocampus of rats. Behavioral and Neural Biology, 58: 16-25.

4. Izquierdo I, Schröder N, Netto CA \& Medina J H (1999). Novelty causes timedependent retrograde amnesia for onetrial avoidance in rats through NMDA receptor- and CaMKII-dependent mechanisms in hippocampus. European J ournal of Neuroscience, 11: 3323-3328.

5. Wolfman C, Izquierdo LA, Schröder N \& Izquierdo I (1999). Intrahippocampal KN62 hinders the memory of habituation acquired alone, but not simultaneously with a water-finding task. Behavioural Pharmacology, 10: 99-104.

6. Izquierdo I \& Medina J H (1997). Memory formation: The sequence of biochemical events in the hippocampus and its connection to activity in other brain structures. Neurobiology of Learning and Memory, 68: 285-316.

7. McGaugh J L (2000). Memory - A century of consolidation. Science, 287: 248-251.

8. Bernabeu $R$, Bevilaqua $L$, Ardenghi $P$, Bromberg E, Schmitz PK, Bianchin M, Izquierdo I \& Medina J H (1997). Involvement of hippocampal D1/D5 receptorCAMP signaling pathways in a late memory consolidation phase of an aversivelymotivated task in rats. Proceedings of the National Academy of Sciences, USA, 94: 1041-1046.

9. Rose SPR (1995). Time-dependent biochemical and cellular processes in memory formation. In: McGaugh J L, Bermúdez-Rattoni F \& Prado-Alcalá RA (Editors), Plasticity in the Central Nervous System: Learning and Memory. Erlbaum, Mahwah, NJ , USA.

10. Izquierdo I, Medina JH, Vianna MRM, Izquierdo LA \& Barros DM (1999). Separate mechanisms for short- and long-term memory. Behavioural Brain Research, 103: 1-11.

11. Vianna MRM, Izquierdo LA, Barros DM, Medina J H \& Izquierdo I (1999). Intrahip- pocampal infusion of an inhibitor of protein kinase A separates short- from longterm memory. Behavioural Pharmacology, 10: 223-227.

12. Walz R, Roesler $R$, Barros DM, de Souza $M M$, Rodrigues C, Sant'Anna MK, Quevedo J , Choi H, Neto WP, DeDavid e Silva TL, Medina J H \& Izquierdo I (1999). Effects of post-training infusions of a mitogen-activated protein kinase kinase inhibitor into the hippocampus or entorhinal cortex on short- and long-term retention of inhibitory avoidance. Behavioural Pharmacology, 10: 723-730.

13. Malenka RC \& Nicoll RC (1999). Longterm potentiation - $A$ decade of progress? Science, 285: 1870-1874.

14. J erusalinsky D, Ferreira MBC, Walz R, da Silva RC, Bianchin M, Ruschel A, Medina J H \& Izquierdo I (1992). Amnesia by infusion of glutamate receptor blockers into the amygdala, hippocampus and entorhinal cortex. Behavioral and Neural Biology, 58: 76-80.

15. Cammarota $M$, Bernabeu $R$, Levi de Stein M , Izquierdo I \& Medina J H (1998). Learning-specific, time-dependent increases in hippocampal $\mathrm{Ca}^{2+} /$ calmodulin-dependent protein kinase II activity and AMPA GluR1 subunit immunoreactivity. European J ournal of Neuroscience, 10: 2669-2676.

16. Tan S-E \& Liang KC (1996). Spatial learning alters calcium/calmodulin-dependent protein kinase II in rats. Brain Research, 711: 234-240.

17. Wolfman $C$, Fin $C$, Dias $M$, Bianchin $M$, Da Silva RC, Schmitz PK, Medina J H \& Izquierdo I (1994). Intra-hippocampal or intra-amygdala infusion of Kn62, a specific inhibitor of calcium/calmodulin-dependent protein kinase II, causes retrograde amnesia in the rat. Behavioral and Neural Biology, 61: 203-205.

18. Walz R, Roesler R, Quevedo J , Sant'Anna MK, Madruga $M$, Rodrigues $C$, Gottfried C, Medina J H \& Izquierdo I (2000). Timedependent impairment of inhibitory avoidance retention by posttraining infusion of a mitogen-activated protein kinase kinase inhibitor into cortical and limbic structures. Neurobiology of Learning and Memory, 73: 11-20.

19. Carew TJ (1996). Molecular enhancement of memory formation. Neuron, 16: 5-8.

20. Ardenghi $P$, Barros DM, Izquierdo LA, Bevilaqua L, Schröder N, Quevedo J, Rodrigues C, Madruga M, Medina J H \& Izquierdo I (1997). Late and prolonged memory modulation in entorhinal and pa- rietal cortex by drugs acting on the CAMP/ protein kinase A signalling pathway. Behavioural Pharmacology, 8: 745-751.

21. Bevilaqua L, Ardenghi P, Schröder N, Bromberg E, Schmitz PK, Schaeffer E, Quevedo J, Bianchin M, Walz R, Medina J H \& Izquierdo I (1997). Drugs acting upon the protein kinase A/CREB pathway modulate memory consolidation when given late after training into rat hippocampus but not amygdala. Behavioural Pharmacology, 8: 331-338.

22. Guzowski J \& McGaugh J L (1997). Antisense oligodeoxynucleotide-mediated disruption of hippocampal cAMP response element binding protein levels impairs consolidation of memory for water maze training. Proceedings of the $\mathrm{Na}$ tional Academy of Sciences, USA, 94: 2693-2698.

23. Bourtchouladze R, Frenguelli B, Blendy J , Cioffi D, Schutz G \& Silva AJ (1994). Deficient long-term memory in mice with targeted mutation of the CAMP-responsive element-binding protein. Cell, 79: 59-68.

24. Schafe GE, Nadel NV, Sullivan GM, Harris A \& LeDoux J E (1999). Memory consolidation for contextual and auditory fear conditioning is dependent upon protein synthesis, PKA and MAP kinase. Learning and Memory, 6: 97-110.

25. Wilson MA \& Tonegawa S (1997). Synaptic plasticity, place cells and spatial memory. Study with second generation knockouts. Trends in Neurosciences, 20: 102-106.

26. Mayford $M$, Bach $M E$, Huang $Y-Y$, Wang L, Hawkins RD \& Kandel ER (1996). Control of memory formation through regulation of a CaM KII transgene. Science, 274: 1678-1683.

27. Abel $T$, Nguyen $P$, Barad $M$, Deuel $T$, Kandel ER \& Bourtchouladze R (1997). Genetic demonstration of a role for PKA in the late phase of LTP and in the hippocampus-based long-term memory. Cell, 88: 615-626.

28. Bourtchouladze R, Abel T, Berman N, Gordon R, Lapidus K \& Kandel ER (1998). Different training procedures recruit either one or two critical periods for contextual memory consolidation, each of which requires protein synthesis and PKA. Learning and Memory, 5: 365-374.

29. Kopf SR \& Baratti CM (1996). Effects of posttraining administration of glucose on retention of a habituation response in mice: participation of a central cholinergic mechanism. Neurobiology of Learning 
and Memory, 65: 253-260.

30. Kopf SR \& Baratti CM (1999). Effects of posttraining administration of insulin on retention of a habituation response in mice: participation of a central cholinergic mechanism. Neurobiology of Learning and Memory, 71: 50-61.

31. Izquierdo LA, Barros DM, Medina JH \& Izquierdo I (2000). Novelty enhances retrieval of one-trial avoidance learning in rats 1 or 31 days after training. Behavioural Brain Research, 117: 215-220.

32. Netto CA, Cavalheiro EA, Carrasco MA, Volkmer N, Dias RD \& Izquierdo I (1985). Response of the rat brain ß-endorphin sys- tem to novelty: Importance of the formix connection. Behavioral and Neural Biology, 43: 37-46.

33. Paxinos $G \&$ Watson $C$ (1986). The Rat Brain in Stereotaxic Coordinates. 2nd edn. Academic Press, San Diego.

34. Martin J H (1991). Autoradiographic estimation of the extent of reversible inactivation produced by microinjection of lidocaine and muscimol in the rat. Neuroscience Letters, 127: 160-164.

35. Vianna MRM, Alonso M, Viola H, Quevedo J, Paris $F$, Furman $M$, Levi de Stein $M$, Medina J H \& Izquierdo I (2000). Role of hippocampal signaling pathways in long- term memory formation for a nonassociative learning task in the rat. Learning and Memory, 7: 333-340.

36. Mitchell J M, Basbaum Al \& Fields HL (2000). A locus and mechanism of action for associative morphine tolerance. $\mathrm{Na}$ ture Neuroscience, 3: 47-53.

37. Roberson ED, English JD, Adams J P, Selcher J C, Kondratick C \& Sweatt J D (1999). The mitogen-activated protein kinase cascade couples PKA and PKC to CAMP response element binding protein phosphorylation in area CAl of hippocampus. J ournal of Neuroscience, 19: 43374348. 